\title{
Molecular characteristics and pathogenicity of porcine epidemic diarrhea virus in some areas of China from 2015 to 2018
}

\section{Linyang Yu}

South China Agricultural University

\section{Jianguo Dong}

Xinyang Agriculture and Forestry University

\section{Shuangyun Wang}

South China Agricultural University

\section{Yanling Liu}

South China Agricultural University

\section{Leyi Zhang}

South China Agrocultural University

\section{Pengshuai Liang}

South China Agricultural University

\section{Lei Wang}

South China Agricultural University

\section{Bin Chen}

Xinyang Agriculture and Forestry University

Li Huang ( $\square$ cnvet19@126.com )

Xinyang Agriculture and Forestry University

Changxu song ( $\nabla$ cxsong2004@163.com )

South China Agricultural University

\section{Research}

Keywords: PEDV, Phylogenetic analysis, S gene, Pathogenicity

Posted Date: July 22nd, 2020

DOI: https://doi.org/10.21203/rs.3.rs-41418/v1

License: (a) (i) This work is licensed under a Creative Commons Attribution 4.0 International License. Read Full License 


\section{Abstract \\ Background}

Since 2010, porcine epidemic diarrhea virus (PEDV) has caused severe diarrhea disease in piglets, which has led to large economic losses in China. To understand the genetic characteristics of PEDV strains that have been circulating in some provinces of China from 2015 to 2018, 362 feces and small intestine samples in pigs were collected and tested.

\section{Methods}

The S gene of PEDV in collected samples were amplified by RT-PCR. A phylogenetic tree was constructed using MEGA6.0 software with the neighbor-joining method to analyze the evolutionary relationship. Nucleotide and deduced amino acid (AA) sequences of $S$ were aligned using the MegAlign program of DNASTAR7.1 software to determine sequence homology. PEDV GDgh16 strain isolation, IFA identification and titer detection were performed in Vero cells. Six 4-day-old healthy colostrum deprived suckling piglets were used for challenging experiment of PEDV GDgh16 strain. Virus copies from the small intestine were detected by RT-qPCR. The other section was stained with the anti-N protein McAb at 1:1000 dilution for immunohistochemical (IHC) examinations.

\section{Results}

The results showed that 160 samples tested positive and the PEDV-positive prevalence was $44.20 \%$. Phylogenetic tree analysis of entire $S$ genes showed that these strains were clustered into four subgroups, G1-b, G1-c, G2-a and G2-b, and that the G2-b strains had become dominant in recent years. Compared with previous strains, these strains had multiple variations in the SP and S1-NTD domains and in the neutralizing epitope of the S protein. Furthermore, we successfully isolated and identified a new virulent G2-b strain, GDgh16, which was well adapted to Vero cells and had a high mortality rate in piglets through challenge experiments.

\section{Conclusions}

Our study provides full insights into the genetic characteristics of prevalent PEDV strains in parts of China, suggesting that the development of novel effective vaccines is necessary and urgent.

\section{Background}

Porcine epidemic diarrhea virus (PEDV) is the pathogen of porcine epidemic diarrhea (PED), which is a severe diarrhea disease in piglets that has the characteristics of severe watery diarrhea, vomiting, dehydration, weight loss and nearly high mortality up to 100\% [1]. PED was sporadic around the world from 1990 to 2009. However, since 2010, an acute and severe outbreak of PED in piglets occurred in China and spread to other Asian countries, causing large economic loss [2-8]. In April 2013, PED suddenly outbreak in the United States which causing many piglets to die, and the mortality rate of Suckling piglets reached $100 \%[9,10]$. It was demonstrated 
that the disease was caused by a highly pathogenic PEDV variant. Compared with the PEDV variant strains, the S genes of classical CV777 and new OH851 had the same insertions and deletions (S-INDEL strains) [11, 12].

The genome of PEDV is approximately $28 \mathrm{~kb}$ in length and consists of seven open reading frames (ORFs), which encode four structural proteins and three non-structural proteins [13]. $S$ is the largest structural protein, which contains neutralizing antibody epitopes and a specific receptor binding site for virus entry [14]. At present, four antigenic epitopes has been characterized in the $S$ protein, including the CO equivalent (COE) domain (aa positions 499-638), the epitopes SS2 (aa positions 748-755) and SS6 (aa positions 764-771), and the epitope 2 C10 (1368 GPRLQPY 1374) $[15,16]$. Because of the vital role of the S protein and extensive mutation of the S gene, it is often used as a target gene for the analysis of virus genetic variation. Based on the S gene,PEDV strains can be classified into genogroup 2 (G2) and genogroup 1 (G1). At present, most isolated recovered in China belong to G2 [17]. Recently, a new mutation in the S gene of PEDV has been reported[18]. Different recombinant PEDV strains have also been reported in different areas of China[19, 20]. Studies have shown that one province in particular has the co-existence of different genotyped PEDV strains. These results indicate that PEDV has been continuing to spread widely to most areas of China and has caused serious economic loss to the pig industry, thereby manifesting the complex evolution of the virus. Therefore, extensive research of the evolutionary pathogenic mechanism is essential in China.

To control the PEDV spread, the classical CV777-derived vaccine has been widely used in many areas of China; however, it cannot provide adequate protection against PEDV invasion. In contrast, the wide-scale use of the vaccines has increased the environment stress and led to PEDV variation to escape immune protest. To further and fully understand the prevalence and evolution of PEDV in South China, in this study, the diarrhea samples of piglets were collected, and the variation of the S genes of PEDV positive samples were analyzed by sequence alignment and a phylogenetic tree.

\section{Materials And Methods}

\section{Sample collection}

A total of 362 diarrheic samples from small intestine tissues or diarrhea feces of suckling piglets in pig farms in five provinces of China (Guangdong, Guangxi, Jiangxi, Hu'nan and Hainan) were collected from June 2015 to October 2018. The piglets had severe watery-diarrhea and dehydration. The diarrhea feces were re-suspended in $1 \mathrm{~mL}$ phosphate buffer saline (PBS) solution in $1.5 \mathrm{~mL}$ Eppendorf tubes. After centrifugation at 10,000 $\times \mathrm{g}$ for $5 \mathrm{~min}, 200 \mu \mathrm{L}$ supernatants were transferred into new tubes for RNA extraction and virus isolation.

\section{RNA extraction and sequencing}

The total RNA of collected supernatants was extracted using TRIzol reagent (TaKaRa) according to the manufacturer's instructions. To extract RNA, reverse transcription PCR (RT-PCR) was performed using three pairs of newly designed primers for PEDV S gene amplification and detection (Table 1). The overlapping three PCR products were identified by $1.5 \%$ agarose gel electrophoresis. The positive PCR products were sequenced by Sangon Biological Engineering Co. Ltd., and the entire sequence of the S gene was obtained by using DNAStar 
7.1 software. The complete $S$ gene sequence was submitted to GenBank, and the accession no. is listed in Table 2.

Table 1

Primers used for PEDV complete $S$ gene amplification

\begin{tabular}{|lll|}
\hline Primer name & Nucleotide sequence, 5'-3' & Size(bp) \\
\hline PEDV S1-F & GGTAAGTTGCTAGTGCGTA & 1630 \\
\hline PEDV S1-R & CACAGAAAGAACTAAACCC & \\
\hline PEDV S2-F & CTGCCATTCAGCGTATTCTTT & 1768 \\
\hline PEDV S2-R & CTGCGAGTTAACAACCTCTTGA & \\
PEDV S3-F & GTGCGCAGTATTACTCTGGT & 1559 \\
\hline PEDV S3-R & AAGAAGACGCTTTAAACAGTG & \\
\hline
\end{tabular}


Table 2

Information of S genes of 62 PEDV isolates

\begin{tabular}{|c|c|c|c|c|c|c|}
\hline No. & Designation & Area & Region & Year & $S(b p)$ & Accession no \\
\hline 1 & FJly15 & Longyan & Fujian & 2015 & 4161 & MN368663 \\
\hline 2 & FJqz15 & Quanzhou & Fujian & 2015 & 4161 & MN368664 \\
\hline 3 & FJzz15 & Zhangzhou & Fujian & 2015 & 4161 & MN368665 \\
\hline 4 & GDgz15-1 & Guangzhou & Guangdong & 2015 & 4161 & MN368666 \\
\hline 5 & GDgz15-2 & Guangzhou & Guangdong & 2015 & 4161 & MN368667 \\
\hline 6 & GDhy15 & Heyuan & Guangdong & 2015 & 4161 & MN368668 \\
\hline 7 & GDhz15 & Huizhou & Guangdong & 2015 & 4161 & MN368669 \\
\hline 8 & GDjm15 & Jiangmen & Guangdong & 2015 & 4161 & MN368670 \\
\hline 9 & GDmm15 & Maoming & Guangdong & 2015 & 4161 & MN368671 \\
\hline 10 & GDsg15-1 & Shaoguan & Guangdong & 2015 & 4161 & MN368672 \\
\hline 11 & GDsg15-2 & Shaoguan & Guangdong & 2015 & 4161 & MN368673 \\
\hline 12 & GDsg15-3 & Shaoguan & Guangdong & 2015 & 4161 & MN368674 \\
\hline 13 & GDzq15-1 & Zhaoqing & Guangdong & 2015 & 4161 & MN368675 \\
\hline 14 & GDzq15-2 & Zhaoqing & Guangdong & 2015 & 4161 & MN368676 \\
\hline 15 & GXnn15 & Nanning & Guangxi & 2015 & 4161 & MN368678 \\
\hline 16 & GZgy15 & Guiyang & Guizhou & 2015 & 4161 & MN368679 \\
\hline 17 & HBhg15 & Huanggang & Hubei & 2015 & 4161 & MN368680 \\
\hline 18 & JXgz15 & Ganzhou & Jiangxi & 2015 & 4161 & MN368681 \\
\hline 19 & JXyc15 & Yichun & Jiangxi & 2015 & 4161 & MN368662 \\
\hline 20 & FJqz16 & Quanzhou & Fujian & 2016 & 4158 & MN368683 \\
\hline 21 & GDfs16 & Foshan & Guangdong & 2016 & 4158 & MN368684 \\
\hline 22 & GDhy16 & Heyuan & Guangdong & 2016 & 4161 & MN368685 \\
\hline 23 & GDhz16 & Huizhou & Guangdong & 2016 & 4161 & MN368686 \\
\hline 24 & GDjm16-1 & Jiangmen & Guangdong & 2016 & 4158 & MN368687 \\
\hline 25 & GDjm16-2 & Jiangmen & Guangdong & 2016 & 4161 & MN368688 \\
\hline 26 & GDjx16 & Jiexi & Guangdong & 2016 & 4158 & MN368689 \\
\hline 27 & GDsg16-1 & Shaoguan & Guangdong & 2016 & 4158 & MN368690 \\
\hline 28 & GDsg16-2 & Shaoguan & Guangdong & 2016 & 4158 & MN368691 \\
\hline 29 & GDyj16 & Ynagjiang & Guangdong & 2016 & 4161 & MN368692 \\
\hline
\end{tabular}




\begin{tabular}{|c|c|c|c|c|c|c|}
\hline No. & Designation & Area & Region & Year & S (bp) & Accession no \\
\hline 30 & GDgh16 & Guanghui & Guangdong & 2016 & 4158 & MG983755 \\
\hline 31 & GDdg17 & Dongguan & Guangdong & 2016 & 4158 & MN368693 \\
\hline 32 & FJfz17-1 & Fuzhou & Fujian & 2017 & 4161 & MN368695 \\
\hline 33 & FJfz17-2 & Fuzhou & Fujian & 2017 & 4161 & MN368696 \\
\hline 34 & FJqz17-1 & Quanzhou & Fujian & 2017 & 4161 & MN368697 \\
\hline 35 & FJqz17-2 & Quanzhou & Fujian & 2017 & 4158 & MN368698 \\
\hline 36 & GDhy17 & Heyuan & Guangdong & 2017 & 4158 & MN368699 \\
\hline 37 & GDhz17 & Huizhou & Guangdong & 2017 & 4158 & MN368700 \\
\hline 38 & GDjm17-1 & Jiangmen & Guangdong & 2017 & 4152 & MN368701 \\
\hline 39 & GDjm17-2 & Jiangmen & Guangdong & 2017 & 4158 & MN368702 \\
\hline 40 & GDjm17-3 & Jiangmen & Guangdong & 2017 & 4161 & MN368703 \\
\hline 41 & GDmm17-1 & Maoming & Guangdong & 2017 & 4158 & MN368704 \\
\hline 42 & GDmm17-2 & Maoming & Guangdong & 2017 & 4158 & MN368705 \\
\hline 43 & GDsg17 & Shaoguan & Guangdong & 2017 & 4161 & MN368706 \\
\hline 44 & HNcz17 & Chenzhou & Hunan & 2017 & 4161 & MN368707 \\
\hline 45 & JXnc17 & Nanchang & Jiangxi & 2017 & 4158 & MN368708 \\
\hline 46 & FJfz18-1 & Fuzhou & Fujian & 2018 & 4161 & MN368710 \\
\hline 47 & FJfz18-2 & Fuzhou & Fujian & 2018 & 4158 & MN368711 \\
\hline 48 & FJqz18 & Quanzhou & Fujian & 2018 & 4158 & MN368712 \\
\hline 49 & GDhy 18-1 & Heyuan & Guangdong & 2018 & 4158 & MN368713 \\
\hline 50 & GDhy18-2 & Heyuan & Guangdong & 2018 & 4158 & MN368714 \\
\hline 51 & GDhy18-3 & Heyuan & Guangdong & 2018 & 4158 & MN368715 \\
\hline 52 & GDhz18 & Huizhou & Guangdong & 2018 & 4158 & MN368716 \\
\hline 53 & GDjm18-1 & Jiangmen & Guangdong & 2018 & 4158 & MN368717 \\
\hline 54 & GDjm18-2 & Jiangmen & Guangdong & 2018 & 4149 & MN368718 \\
\hline 55 & GDmm18-1 & Maoming & Guangdong & 2018 & 4158 & MN368719 \\
\hline 56 & GDmm18-2 & Maoming & Guangdong & 2018 & 4158 & MN368720 \\
\hline 57 & GDsg18-1 & Shaoguan & Guangdong & 2018 & 4158 & MN368721 \\
\hline 58 & GDsg18-2 & Shaoguan & Guangdong & 2018 & 4158 & MN368722 \\
\hline 59 & GDst18 & Shantou & Guangdong & 2018 & 4158 & MN368723 \\
\hline
\end{tabular}




\begin{tabular}{|cllllll|}
\hline No. & Designation & Area & Region & Year & S (bp) & Accession no \\
\hline 60 & GDzj18-1 & Zhanjiang & Guangdong & 2018 & 4155 & MN368724 \\
\hline 61 & GDzj18-2 & Zhanjiang & Guangdong & 2018 & 4161 & MN368725 \\
\hline 62 & SDbz18 & Binzhou & Shandong & 2018 & 4158 & MN368709 \\
\hline
\end{tabular}

\section{S gene sequence analyses}

The representative strains of complete genome sequences that were available in GenBank were collected and used for phylogenetic analyses (Table 3). The phylogenetic tree of all the $S$ genes of the representative strains and isolates was constructed by the neighbor joining method with 1000 bootstrap replicates using Molecular Evolutionary Genetics Analysis (MEGA) software (version 6.0) (http://www.megasoftware.net/). 
Table 3

Information of the representative strains

\begin{tabular}{|c|c|c|c|c|c|c|c|}
\hline Virus Strain & Countries & Year & $\begin{array}{l}\text { accession } \\
\text { no. }\end{array}$ & Virus Strain & Countries & Year & $\begin{array}{l}\text { accession } \\
\text { no. }\end{array}$ \\
\hline CV777 & Belgium & 2001 & AF353511 & 83P-5 & Japan & 2013 & AB548618 \\
\hline JS-2004-2 & China & 2004 & AY653204 & $\begin{array}{l}\text { OKN-1-JPN- } \\
2013\end{array}$ & Japan & 2013 & LC063836 \\
\hline DX-S & China & 2007 & EU031893 & CH-LXC-2014 & China & 2014 & KT388418 \\
\hline LZC & China & 2007 & EF185992 & PEDV-14 & China & 2014 & KM609207 \\
\hline DR13/virulent & Korea & 2007 & DQ862099 & CH-HNQX-3-14 & China & 2014 & KR095279 \\
\hline JS2008 & China & 2008 & KC109141 & CH-HNYF-14 & China & 2014 & KP890336 \\
\hline BJ-2011-1 & China & 2011 & JN825712 & $\begin{array}{l}\text { CH-GD-22- } \\
2014\end{array}$ & China & 2014 & KP870132 \\
\hline CH-JLCC-2011 & China & 2011 & JQ638920 & $\begin{array}{l}\text { USA- } \\
\text { Minnesota271- } \\
2014\end{array}$ & USA & 2014 & KR265813 \\
\hline $\mathrm{CH}-\mathrm{S}$ & China & 2011 & JN547228 & MEX-124-2014 & USA & 2014 & KJ645700 \\
\hline CH-FJND-1-2011 & China & 2011 & JN543367 & OH851 & USA & 2014 & KJ399978 \\
\hline SM98 & Korea & 2011 & GU937797 & $\begin{array}{l}\text { USA-Ohio126- } \\
2014\end{array}$ & USA & 2014 & KJ645702 \\
\hline CH-GXNN-2012 & China & 2012 & JX018179 & $\begin{array}{l}\text { AOM-2-JPN- } \\
2014\end{array}$ & Japan & 2014 & LC063837 \\
\hline GD-A & China & 2012 & JX112709 & $\begin{array}{l}\text { AOM-3-JPN- } \\
2014\end{array}$ & Japan & 2014 & LC063833 \\
\hline GD-B & China & 2012 & JX088695 & $\begin{array}{l}\text { KCH-2-JPN- } \\
2014\end{array}$ & Japan & 2014 & LC063845 \\
\hline CH-SDDZ-2012 & China & 2012 & KU133240 & KPEDV-9 & Korea & 2014 & KF898124 \\
\hline $\mathrm{AH} 2012$ & China & 2012 & KC210145 & KNU-1310 & Korea & 2014 & KJ451045 \\
\hline JS-HZ2012 & China & 2012 & KC210147 & KNU-1401 & Korea & 2014 & KJ451047 \\
\hline CH-ZJCX-1-2012 & China & 2012 & KF840537 & KNU-1406-1 & Korea & 2014 & KM403155 \\
\hline CH9-FJ & China & 2012 & JQ979287 & $\begin{array}{l}\text { L00721-GER- } \\
2014\end{array}$ & Germany & 2014 & LM645057 \\
\hline CV777/attenuated & China & 2012 & JN599150 & FR-001-2014 & France & 2014 & KR011756 \\
\hline $\mathrm{CH} 7$ & China & 2012 & JQ239435 & PEDV-WS & China & 2015 & KM609213 \\
\hline $\mathrm{CH}-\mathrm{HBX} \times 2-11$ & China & 2013 & JX501319 & $\begin{array}{l}\mathrm{CH}-\mathrm{XBC}-01- \\
2015\end{array}$ & China & 2015 & KR296677 \\
\hline CH-ZMDZY-11 & China & 2013 & KC196276 & $\begin{array}{l}\text { CH-YGC-01- } \\
2015\end{array}$ & China & 2015 & KR296678 \\
\hline
\end{tabular}




\begin{tabular}{|c|c|c|c|c|c|c|c|}
\hline Virus Strain & Countries & Year & $\begin{array}{l}\text { accession } \\
\text { no. }\end{array}$ & Virus Strain & Countries & Year & $\begin{array}{l}\text { accession } \\
\text { no. }\end{array}$ \\
\hline CH-SBC-03-2013 & China & 2013 & KC787542 & $\begin{array}{l}\text { CH-ZWBZa-01- } \\
2015\end{array}$ & China & 2015 & KR296680 \\
\hline CH-YNKM-8-2013 & China & 2013 & KF761675 & CH-HNAY-2015 & China & 2015 & KR809885 \\
\hline CH-JX-1-2013 & China & 2013 & KF760557 & $\begin{array}{l}\text { CH-JPYC-02- } \\
2015\end{array}$ & China & 2015 & JN547228 \\
\hline $\mathrm{CH}-\mathrm{HBQX}-10$ & China & 2013 & JX501318 & $\begin{array}{l}\text { TW-Pingtung- } \\
63\end{array}$ & China & 2015 & KP276250 \\
\hline $\begin{array}{l}\text { USA-Indiana- } \\
17846-2013\end{array}$ & USA & 2013 & KF452323 & CBR2 & Thailand & 2015 & KR610994 \\
\hline $\begin{array}{l}\text { USA-lowa-16465- } \\
2013\end{array}$ & USA & 2013 & KF452322 & HUA-PED47 & Korea & 2015 & KP455314 \\
\hline $\begin{array}{l}\text { USA- } \\
\text { Minnesota90- } \\
2013\end{array}$ & USA & 2013 & KJ645682 & HUA-PED45 & Korea & 2015 & KP455313 \\
\hline $\mathrm{MN}$ & USA & 2013 & KF468752 & HUA-PED67 & Korea & 2015 & KP455319 \\
\hline IA1 & USA & 2013 & KF468753 & $\begin{array}{l}\text { 15V010-BEL- } \\
2015\end{array}$ & Belgium & 2015 & KR003452 \\
\hline IA2 & USA & 2013 & KF468754 & $\begin{array}{l}\text { CH-HNCD- } \\
2016\end{array}$ & China & 2016 & MF152600 \\
\hline NPL-PEDV-2013 & USA & 2013 & KJ778615 & HUA-14PED 96 & Korea & 2016 & KT941120 \\
\hline $\begin{array}{l}\text { USA-Colorado- } \\
2013\end{array}$ & USA & 2013 & KF272920 & 14JM-226 & Japan & 2018 & KY619763 \\
\hline NK & Japan & 2013 & AB548623 & 14JM-126 & Japan & 2018 & KY619740 \\
\hline MK & Japan & 2013 & AB548624 & 13JM-291 & Japan & 2018 & KY619768 \\
\hline
\end{tabular}

\section{Virus isolation}

Vero cells which grown in a 24-well cell culture plate were infected with the previous supernatants and were maintained in Dulbecco's modified Eagle's medium (DMEM) (Thermo Scientific) contains 7ug/ml trypsin without EDTA (Thermo Scientific). The cells were monitored daily for cytopathic effects (CPE). When the CPE appeared in $70 \%$ of the cells, the cells were fixed with anhydrous ethanol and immunofluorescence assay (IFA) was performed using the anti-N protein McAb (Alpha Diagnostic International Inc, Cat\#PEDV12-F, USA) at 1:1000 dilution.

\section{Titer detection for the virus growth curve}


Vero cells cultured in 24-well cell culture plates were infected with PEDV at a MOI 0.01. The cells and supernatants were collected at 12, 24, 36, 48, 60, 72 and 96 hours postinfection (hpi). Then, the cells were frozen and thawed three times. After centrifugation at $10,000 \times \mathrm{g}$ for $5 \mathrm{~min}$ at $4{ }^{\circ} \mathrm{C}$, the supernatants were collected and $\mathrm{TCID}_{50}$ was determined using a microtitration infection assay.

\section{Piglet challenge experiment}

To determine the virulence of isolated strain GDgh16, six 4-day-old healthy colostrum deprived suckling piglets were obtained and were artificially fed with bovine milk from birth. All the piglets without colostrum were randomly divided into two groups with three piglets in each group. One group was challenged orally with $0.5 \mathrm{~mL}$ PEDV at $10^{5.0} \mathrm{TCID}_{50} / \mathrm{mL}$. Then, the other group received a cell culture medium. The small intestine samples of the euthanized 48 hours post challenge piglets were collected in duplicate. One was crushed in a grinder with $2 \mathrm{~mL}$ PBS. Then, the crushed intestine was centrifuged at $10,000 \times \mathrm{g}$ for $10 \mathrm{~min}$ at $4{ }^{\circ} \mathrm{C}$. Next, the supernatants were collected and the RNA was extracted. Finally, virus copies from the small intestine were detected by realtime quantitative PCR (RT-qPCR). The other section was stained with the anti-N protein McAb (Alpha Diagnostic International Inc, Cat\#PEDV12-F, USA) at 1:1000 dilution for immunohistochemical (IHC) examinations.

\section{Statistical analysis}

The numerical data were expressed as the mean \pm SD, and the data were analyzed using GraphPad Prism software (version 5.02 for Windows; GraphPad Software Inc.). Differences between groups were assessed using ANOVA. Differences were considered statistically significant at a $P$ value of $<0.05$ and were extremely significant at a value of $\mathrm{P}<0.01$ or $\mathrm{P}<0.001$.

\section{Results}

\section{PEDV detection and phylogenetic analysis of the $S$ gene}

Of all the 362 feces and small intestine samples being tested, 160 samples were PEDV positive (44.20\%) from 2015 to 2018, and the positive prevalence was 44.83\%(26 positive samples and 58 test samples), $66.67 \%(46$ positive samples and 69 test samples), 42.86\%(27 positive samples and 63 test samples),35.47\%(61 positive samples and 172 test samples) in 2015, 2016, 2017 and 2018, respectively. The positive prevalence of 2016 was the highest, and that of 2018 was the lowest. Sequence alignment showed that all these strains shared 92.9-100\% homology for nucleotides and $91-100 \%$ identity for amino acids. Compared to the reference strain CV777, these strains shared 93.1-96.8\% nucleotide homology and 91.5-96.8\% amino acid identity. These strains shared $93.8-99 \%$ nucleotide homology and $92.5-98.9 \%$ amino acid identity with Chinese PEDV strains.

Sixty-two S genes of the tested strains and the representative strains that were published in GenBank were analyzed by a phylogenetic tree. As shown in Fig. 1, the phylogenetic analysis showed that these strains could be divided into two groups, namely, G1 and G2. G1 included the classical strains (CV777 and SM98) and some isolates from China, USA and Japan after 2010. Thus, G1 was further divided into three subgroups: G1-a, G1-b and G1-c. G1-a and G1-b were classical S-INDEL strains, and G1-c was a new S-INDEL strain. G2 was a non-SINDEL strain and was also divided into two subgroups, G2-a and G2-b, which consisted of a number of severely 
virulent strains from all over the world since 2010. The strains in our study belonged to G1-b, G1-c, G2-a and G2b. One strain, GDjm18-2, was categorized as subtype G1-b, which included classical vaccine strains CV777/attenuated and JS2008. One strain GDjm17-1 belonged to the G1-c cluster. The other strains that were identified in our study formed eight clusters. In these strains, 25 isolates from Guangdong, 3 isolates from Fujian and 1 isolate from Jiangxi formed three clusters and belonged to G2-b, having high similarity with GD-A and $\mathrm{CH}$ GXNN-2012. The other 34 isolates formed five clusters and belonged to G2-a. In the 34 strains, JXyc15 has a close relationship with the $\mathrm{C} 4$ cluster (North American strains). The other strains had a closer identity with $\mathrm{CH}$ ZMDZ-11, CH-HNAY-2015 and CH-HNCDE-2016L. As shown in Table 4, all the isolated strains from 2015 belonged to G2-a (100\%). In 2016 and 2017, there were 46.15\% and 43.75\% isolated strains belonging to G2-a, respectively. Compared with G2-a, the rate slightly increased, and there were $53.84 \%$ and $50 \%$ isolated strains belonging to G2-b, respectively. However, in 2018 , there were $72.22 \%$ isolated strains that belonged to $\mathrm{G} 2-\mathrm{b}$, which was much higher than that of G2-a in 2017 (22.22\%).

Table 4

The PEDV positive prevalence of different groups of tested strains in our study.

\begin{tabular}{|lllll|}
\hline Group & 2015 & 2016 & 2017 & 2018 \\
\hline G1-b & 0 & 0 & 0 & $5.56 \%$ \\
\hline G1-c & 0 & 0 & $6.25 \%$ & 0 \\
\hline G2-a & $100 \%$ & $46.15 \%$ & $43.75 \%$ & $22.22 \%$ \\
\hline G2-b & 0 & $53.84 \%$ & $50 \%$ & $72.22 \%$ \\
\hline
\end{tabular}

\section{Amino acid sequence analysis of the neutralizing epitope in the S protein}

To analyze the genetic characteristics of the South China PEDV strains, the deduced amino acids of the S protein isolated in our study were aligned and compared with that of the representative PEDV strains, including strains from G1-a (CV777 and DR13 virulent), G1-b (CV777-attenuated), G1-c (OH851 and CH-ZWZBa-01-2015), G2-a (CH-HNQX-3-14, CH-HNAY-2015, CH-ZMDZY-11) and G2-b (CH-GXNN-2012, CD-A). As shown in Fig. 2, compared to the CV777 strain, the G1-b strain GDjm18-2 had three amino acid (AA) substitutions in the COE domain, and 1 AA substitution in the epitope SS6. The G2-a strains had AA substitutions at thirty-five positions in the COE domain, at two positions in the epitope SS2 and at five positions in the epitope SS6. In these positions, many new AA substitutions have been found in the COE regions of the G2-a strains, including 502 (S/P), 507 (P/M), 510 (N/S), 516 (N/D), 522 (S/A), 527 (S/G), 533 (A/V), 535 (D/E), 547 (D/E), 559 (V/I or A), 562 (S/D), 567 (S/A), 568 (K/T or N), 570 (Q/H), 571 (D/N or Y), 575 (P/L), 580 (S/A), 588 (S/G), 594 (T/R or C), 608 $(\mathrm{Y} / \mathrm{H}), 613$ (S/I or G), 614 (G/V), 626 (K/E or S), and 637 (L/ F or S). 2 C10 was conserved in all G2-a strains. In the G2-a strains, GDhz16 had four continuous AA mutations in the epitope SS6, which was different from that of the other strains and the reference strains. Compared to the CV777 strain, except for having the AA substitution at one position in three epitopes (SS2, SS6 and 2C10), the G2-b strains had AA substitutions at seventeen positions in the COE domain. In addition to the common AA mutations that were similar to the reference strains in G2-b, there were novel AA substitutions at eight positions in the COE regions, including 504 (V/L), 510 (N/D), 535 (D/H), 542 (S/H), 567 (S/Y), $614(\mathrm{G} / \mathrm{V}), 626(\mathrm{~K} / \mathrm{T})$, and $637(\mathrm{~L} / \mathrm{V})$.

\section{Mutated amino acid number analysis of different domains in the S protein}


To further analyze the AA mutations in different domains of the $S$ protein in the isolates, the different domains of the S protein were aligned with CV777, and the average number of AA mutations each year were computed. The S protein could be divided into an S1 protein and an S2 protein; the S1 protein contained four domains: SP (1-18), S1-NTD (19-233), COE and RBD (501-629). The S2 protein included five domains: SS6 (764-771), HR1 (978-1117), HR2 (1274-1313), TM (1324-1346) and 2C10 (1368-1374). The previous data indicated that $2 \mathrm{C} 10$ was conserved, so we did not analyze the $2 \mathrm{C} 10$ domain. As shown in Fig. 3, compared with the S2 protein sequence in these strains, S1 had more AA mutations. From 2015 to 2018, the mutated AA numbers of S1 maintained a high level, but that of S2 decreased. Furthermore, the mutated AA numbers of SP (1-18) and S1NTD (19-233) slightly increased. However, the mutated AA numbers of the COE and RBD domain decreased. SS6, HR1, HR2 and TM in the S2 protein did not obviously change from 2015 to 2018.

\section{Discussion}

At present, PEDV has become a vital viral causing diarrhea and has caused much damage to pig farms worldwide. Because there is no effective vaccine against the emerging prevalent strain in China, the variant PEDV strain has been prevalent in many farms of different areas[21]. Considering the viral variant and limited protection of commercial vaccines, it is necessary to fully understand the genetic variation and epidemiology of PEDV for next-generation vaccine development.

In our study, the genetic variation of PEDV in parts of China was analyzed from 2015 to 2018.

The S gene encodes the largest structural proteins and could stimulate the body to produce neutralizing antibodies. Because of its extensive variant, the $S$ gene has been commonly used as a target gene in studies on the genome characteristics of PEDV[22]. Phylogenetic analysis showed that the strains of four subgroups existed from 2015 to 2018, and G2-a and G2-b are the two most prevalent subgroups in China. From 2015 to 2018, eight strains that belonged to four subgroups (G1-b, G1-c, G1-a and G1-b) were epidemic in Jiangmen of Guangdong, which suggested that PEDV had mutated widely and the epidemic of PEDV was becoming more complex. These results agree with Wen et al.'s report[23]. In 2015, all the isolated strains belonged to G2-a, but in 2018 , there were $72.22 \%$ strains belonging to $\mathrm{G} 2$-b, and only $22.22 \%$ strains belonging to $\mathrm{G} 2$-a. Interestingly, different from G2-a, which included the strains of other countries, such as America, South Korea, and Japan, the G2-b subgroup only contained Chinese-isolated strains. Combined with previous studies, these results suggest that G2-b strains might be the dominant strains in the future in China [24, 25].

The S protein is much more variable, and many studies showed that the AA changes in the S protein might affect the virulence and pathogenicity. Our study showed that the number of AA mutations in the SP1 and S1NTD domains increased in 2017 and 2018. It had been reported that S1-NTD might be a vital domain related to viral virulence [26, 27]. The conformation change of S1-NTD might be related to the high pathogenicity of the PEDV strain FJzz1 $[24,28]$. Recently, increasingly more virulent PEDV strains emerged $[24,28,29]$. Whether these mutations changed the major conformations and altered the pathogenicity of these strains will be further explored in the future. Our data showed that the positive rate increased from 2015 to 2016, but it decreased from 2016 to 2018, which might be due to the improvement of disease prevention and control strategies. Many pig farms used the mode of "feed-back" to give sows immunity for protecting piglets against PEDV invasion. This was an effective measure to prevent PED, but a risk of virus dispersal also existed, which was why many recombinant PEDV strains were reported [30-34].

Page 12/22 
At present, four neutralizing epitopes of PEDV S protein have been determined, which were the COE domain (499-638), epitope SS2 (748-755), epitope SS6 (764-771) and epitope 2C10 (1368-1374) [15, 16]. In our study, there were AA changes in as many as 35 positions in the COE domain. Moreover, one strain, GDhz16, had four continuous AA mutations in epitope SS6. Epitopes SS2 and 2C10 also had AA substitutions. Because of the mutation, especially some insertions and deletions in the $S$ protein, antigenicity, pathogenicity and neutralization properties of isolated strains have changed[35,36]. That was why the prototype strain CV777-derived vaccine could protect against the disease induced by classical strains but not prevent the disease induced by variant strains $[37,38]$. Whether these AA changes affect the antigenicity and neutralization properties of the four neutralizing epitopes needs be explored in the future.

Based on previous epidemiological and clinical observations of field strains since 2010, the emerging G2 strains were highly pathogenic[39]. To investigate the pathogenicity of isolated variant strains, three piglets were infected orally with GDgh16. The results showed that the piglets in the infected group began to have clinical signs of diarrhea at $12 \mathrm{~h}$, and the piglets developed a typical symptom of PED at $16 \mathrm{~h}$. The morbidity reached $100 \%$. The piglets began to die at $24 \mathrm{hpi}$, and all had died by $48 \mathrm{hpi}$. Moreover, the small intestine had high viral copies and many viral antigens, which indicated that GDgh16 was a highly pathogenic strain. Other researchers demonstrated that different types of pigs infected with variant PEDV strains shared consistent outcomes[4043]. These results indicated that the variant strains were a large threat to the pig industry, and how to control the PED spread has become a critical issue.

\section{Conclusion}

The PEDV strains circulating in parts of China from 2015 to 2018 were clustered into four subgroups: G1-b, G1-c, G2-a and G2-b. The G2-b strains became dominant in 2018. Compared with previous strains, these strains had multiple variations in the SP and S1-NTD domain and in the neutralizing epitope of the S protein. Furthermore, we successfully isolated and identified a new virulent G2-b strain, GDgh16, which was well adapted to Vero cells and had a high mortality rate in piglets. Our study provides full insight into the genetic characteristics of prevalent PEDV strains in parts of China, which suggests that the development of novel effective vaccines is necessary and pressing.

\section{Abbreviations}

PEDV: Porcine epidemic diarrhea virus; PED: Porcine epidemic diarrhea; ORFs: Open reading frames; S: Spike; AA: Amino acid; PBS: Phosphate buffer saline; RT-PCR: Reverse transcription polymerase chain reaction; MEGA: Molecular Evolutionary Genetics Analysis; DMEM: Dulbecco's modified Eagle's medium; CPE: Cytopathic effects; IFA: Immunofluorescence assay; IHC: Immunohistochemical; McAb: Monoclonal antibody; hpi: Hour post infection; S-INDEL: Same insertions and deletions; COE: CO equivalent; SS2: Amino acid positions 748-755; SS6: Amino acid positions 764-771; 2C10: 1368 GPRLQPY 1374; G1: Genogroup 1; G2: Genogroup 2.

\section{Declarations}

\section{Acknowledgements}


This work was supported by the National Key Research and Development Program of China (2018YFD0501102), the Guangdong Rural Revitalization Strategy Program (201817SY0002), the National Key Technologies R\&D Program (2015BAD12B02-5), the Henan Scale Pig Farm Major Disease Purification and Innovative Technology Team, the Key and Cultivation Discipline of Xinyang Agriculture and Forestry University (ZDXK201702) and University-level Science and Technology Innovation Team (CXTD-201801), Science and Technology Innovation Team Construction Project of Xinyang Agriculture and Forestry University, Youth Fund Project of Xinyang Agriculture and Forestry University (2019LG012).

\section{Funding}

This work was supported by the National Key Research and Development Program of China (2018YFD0501102), the Guangdong Rural Revitalization Strategy Program (201817SY0002), the National Key Technologies R\&D Program (2015BAD12B02-5), the Henan Scale Pig Farm Major Disease Purification and Innovative Technology Team, the Key and Cultivation Discipline of Xinyang Agriculture and Forestry University (ZDXK201702) and University-level Science and Technology Innovation Team (CXTD-201801), Science and Technology Innovation Team Construction Project of Xinyang Agriculture and Forestry University, Youth Fund Project of Xinyang Agriculture and Forestry University (2019LG012).

\section{Availability of data and materials}

Genetic data presented in this paper are publicly available via GenBank.

\section{Authors' contributions}

Conceived and designed the experiments: Linyang Yu, Jianguo Dong, Li Huang, Changxu Song. Performed the experiments: Linyang Yu, Jianguo Dong, Shuangyun Wang, Yanling Liu , Leyi Zhang, Pengshuai Liang, Lei Wang, Bin Chen. Analyzed the data and wrote the paper: Linyang Yu, Jianguo Dong, Li Huang, Changxu Song. All authors read and approved the final manuscript.

\section{Ethical Statement}

All of the samples were collected according to the animal ethics regulations of the National Engineering Center for Swine Breeding Industry (NECSBI 2015-16).

\section{Consent for Publication}

Not applicable.

\section{Competing interests}

The authors declare no conflicts of interest.

\section{References}

1. Pensaert MB, de Bouck P. A new coronavirus-like particle associated with diarrhea in swine. Arch Virol. 1978;58:243-7. 
2. Boniotti MB, Papetti A, Lavazza A, Alborali G, Sozzi E, Chiapponi C, Faccini S, Bonilauri P, Cordioli P, Marthaler D. Porcine Epidemic Diarrhea Virus and Discovery of a Recombinant Swine Enteric Coronavirus, Italy. Emerg Infect Dis. 2016;22:83-7.

3. Kim YK, Cho YY, An BH, Lim SI, Lim JA, Cho IS, Le VP, An DJ. Molecular characterization of the spike and ORF3 genes of porcine epidemic diarrhea virus in the Philippines. Arch Virol. 2016;161:1323-8.

4. Pasick J, Berhane Y, Ojkic D, Maxie G, Embury-Hyatt C, Swekla K, Handel K, Fairles J, Alexandersen S. Investigation into the role of potentially contaminated feed as a source of the first-detected outbreaks of porcine epidemic diarrhea in Canada. Transbound Emerg Dis. 2014;61:397-410.

5. Steinrigl A, Fernandez SR, Stoiber F, Pikalo J, Sattler T, Schmoll F. First detection, clinical presentation and phylogenetic characterization of Porcine epidemic diarrhea virus in Austria. Bmc Vet Res. 2015;11:310.

6. Sun RQ, Cai RJ, Chen YQ, Liang PS, Chen DK, Song CX. Outbreak of porcine epidemic diarrhea in suckling piglets, China. Emerg Infect Dis. 2012;18:161-3.

7. Tian Y, Yu Z, Cheng K, Liu Y, Huang J, Xin Y, Li Y, Fan S, Wang T, Huang G, et al. Molecular characterization and phylogenetic analysis of new variants of the porcine epidemic diarrhea virus in Gansu, China in 2012. Viruses. 2013;5:1991-2004.

8. Sung MH, Deng MC, Chung YH, Huang YL, Chang CY, Lan YC, Chou HL, Chao DY. Evolutionary characterization of the emerging porcine epidemic diarrhea virus worldwide and 2014 epidemic in Taiwan. Infect Genet Evol. 2015;36:108-15.

9. Stevenson GW, Hoang H, Schwartz KJ, Burrough ER, Sun D, Madson D, Cooper VL, Pillatzki A, Gauger P, Schmitt BJ, et al. Emergence of Porcine epidemic diarrhea virus in the United States: clinical signs, lesions, and viral genomic sequences. J Vet Diagn Invest. 2013;25:649-54.

10. Jung K, Saif LJ. Porcine epidemic diarrhea virus infection: Etiology, epidemiology, pathogenesis and immunoprophylaxis. Vet J. 2015;204:134-43.

11. Mesquita JR, Hakze-van DHR, Almeida A, Lourenco M, van der Poel WH, Nascimento MS. Outbreak of Porcine Epidemic Diarrhea Virus in Portugal, 2015. Transbound Emerg Dis. 2015;62:586-8.

12. Wang L, Byrum B, Zhang Y. New variant of porcine epidemic diarrhea virus, United States, 2014. Emerg Infect Dis. 2014;20:917-9.

13. Jarvis MC, Lam HC, Zhang Y, Wang L, Hesse RA, Hause BM, Vlasova A, Wang Q, Zhang J, Nelson MI, et al. Genomic and evolutionary inferences between American and global strains of porcine epidemic diarrhea virus. Prev Vet Med. 2016;123:175-84.

14. Wang D, Ge X, Chen D, Li J, Cai Y, Deng J, Zhou L, Guo X, Han J, Yang H. The S Gene Is Necessary but Not Sufficient for the Virulence of Porcine Epidemic Diarrhea Virus Novel Variant Strain BJ2011C. J Viro/ 2018, 92.

15. Chang SH, Bae JL, Kang TJ, Kim J, Chung GH, Lim CW, Laude H, Yang MS, Jang YS. Identification of the epitope region capable of inducing neutralizing antibodies against the porcine epidemic diarrhea virus. Mol Cells. 2002;14:295-9.

16. Sun D, Feng L, Shi H, Chen J, Cui X, Chen H, Liu S, Tong Y, Wang Y, Tong G. Identification of two novel B cell epitopes on porcine epidemic diarrhea virus spike protein. Vet Microbiol. 2008;131:73-81.

17. Zhang Q, Liu X, Fang Y, Zhou P, Wang Y, Zhang Y. Detection and phylogenetic analyses of spike genes in porcine epidemic diarrhea virus strains circulating in China in 2016-2017. Virol J. 2017;14:194. 
18. Liu X, Zhang Q, Zhang L, Zhou P, Yang J, Fang Y, Dong Z, Zhao D, Li W, Feng J, et al. A newly isolated Chinese virulent genotype Gllb porcine epidemic diarrhea virus strain: Biological characteristics, pathogenicity and immune protective effects as an inactivated vaccine candidate. Virus Res. 2019;259:1827.

19. Wang P, Zhu J, Liu X, Guo J, Gu X, Ruan W. Isolation and recombinant analysis of variants of porcine epidemic diarrhea virus strains from Beijing, China. Virus Disease. 2019;30:294-301.

20. Chen N, Li S, Zhou R, Zhu M, He S, Ye M, Huang Y, Li S, Zhu C, Xia P, Zhu J. Two novel porcine epidemic diarrhea virus (PEDV) recombinants from a natural recombinant and distinct subtypes of PEDV variants. Virus Res. 2017;242:90-5.

21. Li W, Li H, Liu Y, Pan Y, Deng F, Song Y, Tang X, He Q. New variants of porcine epidemic diarrhea virus, China, 2011. Emerg Infect Dis. 2012;18:1350-3.

22. Chen J, Liu X, Shi D, Shi H, Zhang X, Li C, Chi Y, Feng L. Detection and molecular diversity of spike gene of porcine epidemic diarrhea virus in China. Viruses. 2013;5:2601-13.

23. Wen Z, Li J, Zhang Y, Zhou Q, Gong L, Xue C, Cao Y. Genetic epidemiology of porcine epidemic diarrhoea virus circulating in China in 2012-2017 based on spike gene. Transbound Emerg Dis. 2018;65:883-9.

24. Chen P, Wang K, Hou Y, Li H, Li X, Yu L, Jiang Y, Gao F, Tong W, Yu H, et al. Genetic evolution analysis and pathogenicity assessment of porcine epidemic diarrhea virus strains circulating in part of China during 2011-2017. Infect Genet Evol. 2019;69:153-65.

25. Yu J, Chai X, Cheng Y, Xing G, Liao A, Du L, Wang Y, Lei J, Gu J, Zhou J. Molecular characteristics of the spike gene of porcine epidemic diarrhoea virus strains in Eastern China in 2016. Virus Res. 2018;247:47-54.

26. Hou Y, Lin CM, Yokoyama M, Yount BL, Marthaler D, Douglas AL, Ghimire S, Qin Y, Baric RS, Saif LJ, Wang Q. Deletion of a 197-Amino-Acid Region in the N-Terminal Domain of Spike Protein Attenuates Porcine Epidemic Diarrhea Virus in Piglets. J Virol 2017, 91.

27. Su Y, Hou Y, Prarat M, Zhang Y, Wang Q. New variants of porcine epidemic diarrhea virus with large deletions in the spike protein, identified in the United States, 2016-2017. Arch Virol. 2018;163:2485-9.

28. Liu X, Zhang Q, Zhang L, Zhou P, Yang J, Fang Y, Dong Z, Zhao D, Li W, Feng J, et al. A newly isolated Chinese virulent genotype Gllb porcine epidemic diarrhea virus strain: Biological characteristics, pathogenicity and immune protective effects as an inactivated vaccine candidate. Virus Res. 2019;259:1827.

29. Zhang L, Liu X, Zhang Q, Zhou P, Fang Y, Dong Z, Zhao D, Li W, Feng J, Zhang Y, Wang Y. Biological characterization and pathogenicity of a newly isolated Chinese highly virulent genotype Glla porcine epidemic diarrhea virus strain. Arch Virol. 2019;164:1287-95.

30. Chen N, Li S, Zhou R, Zhu M, He S, Ye M, Huang Y, Li S, Zhu C, Xia P, Zhu J. Two novel porcine epidemic diarrhea virus (PEDV) recombinants from a natural recombinant and distinct subtypes of PEDV variants. Virus Res. 2017;242:90-5.

31. Wang P, Zhu J, Liu X, Guo J, Gu X, Ruan W. Isolation and recombinant analysis of variants of porcine epidemic diarrhea virus strains from Beijing, China. Virus Disease. 2019;30:294-301.

32. Li B, Liu H, He K, Guo R, Ni Y, Du L, Wen L, Zhang X, Yu Z, Zhou J, et al. Complete genome sequence of a recombinant porcine epidemic diarrhea virus strain from eastern china. Genome Announc. 2013;1:e10513. 
33. Li K, Song D, Zhang F, Gong W, Guo N, Li A, Zhou X, Huang D, Ye Y, Tang Y. Complete Genome Sequence of a Recombinant Porcine Epidemic Diarrhea Virus Strain, CH/JXJA/2017, Isolated in Jiangxi, China, in 2017. Genome Announc 2018, 6.

34. Li R, Qiao S, Yang Y, Guo J, Xie S, Zhou E, Zhang G. Genome sequencing and analysis of a novel recombinant porcine epidemic diarrhea virus strain from Henan, China. Virus Genes. 2016;52:91-8.

35. Park S, Kim S, Song D, Park B. Novel porcine epidemic diarrhea virus variant with large genomic deletion, South Korea. Emerg Infect Dis. 2014;20:2089-92.

36. Zhang X, Pan Y, Wang D, Tian X, Song Y, Cao Y. Identification and pathogenicity of a variant porcine epidemic diarrhea virus field strain with reduced virulence. Virol J. 2015;12:88.

37. Li W, Li H, Liu Y, Pan Y, Deng F, Song Y, Tang X, He Q. New variants of porcine epidemic diarrhea virus, China, 2011. Emerg Infect Dis. 2012;18:1350-3.

38. Puranaveja S, Poolperm P, Lertwatcharasarakul P, Kesdaengsakonwut S, Boonsoongnern A, Urairong K, Kitikoon P, Choojai P, Kedkovid R, Teankum K, Thanawongnuwech R. Chinese-like strain of porcine epidemic diarrhea virus, Thailand. Emerg Infect Dis. 2009;15:1112-5.

39. Lin CM, Saif LJ, Marthaler D, Wang Q. Evolution, antigenicity and pathogenicity of global porcine epidemic diarrhea virus strains. Virus Res. 2016;226:20-39.

40. Madson DM, Arruda PH, Magstadt DR, Burrough ER, Hoang H, Sun D, Bower LP, Bhandari M, Gauger PC, Stevenson GW, et al. Characterization of Porcine Epidemic Diarrhea Virus Isolate US/lowa/18984/2013 Infection in 1-Day-Old Cesarean-Derived Colostrum-Deprived Piglets. Vet Pathol. 2016;53:44-52.

41. Chen Q, Gauger PC, Stafne MR, Thomas JT, Madson DM, Huang H, Zheng Y, Li G, Zhang J. Pathogenesis comparison between the United States porcine epidemic diarrhoea virus prototype and S-INDEL-variant strains in conventional neonatal piglets. J Gen Virol. 2016;97:1107-21.

42. Lin CM, Annamalai T, Liu X, Gao X, Lu Z, El-Tholoth M, Hu H, Saif LJ, Wang Q. Experimental infection of a US spike-insertion deletion porcine epidemic diarrhea virus in conventional nursing piglets and crossprotection to the original US PEDV infection. Vet Res. 2015;46:134.

43. Thomas JT, Chen Q, Gauger PC, Gimenez-Lirola LG, Sinha A, Harmon KM, Madson DM, Burrough ER, Magstadt DR, Salzbrenner HM, et al. Effect of Porcine Epidemic Diarrhea Virus Infectious Doses on Infection Outcomes in Naive Conventional Neonatal and Weaned Pigs. Plos One. 2015;10:e139266.

\section{Figures}




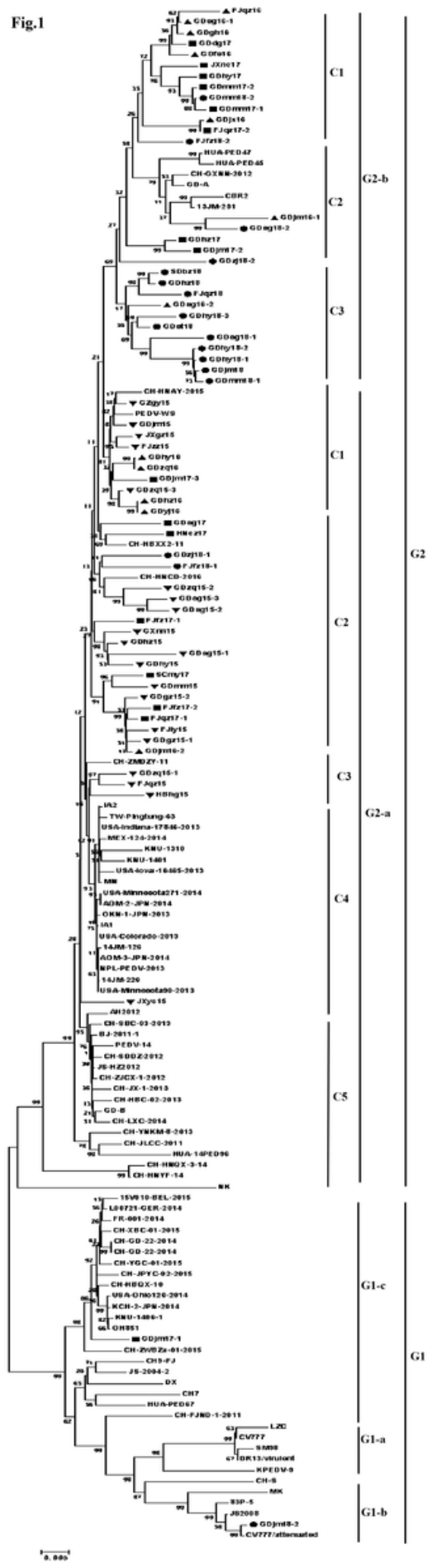

\section{Figure 1}

Phylogenetic tree based on the complete $S$ genes of 62 Chinese PEDV strains identified in this study and in other global reference strains. The tree was constructed by the neighbor-joining method in the MEGA V.6.0 program. The Chinese PEDV strains in this study are marked by black triangle, black square and solid circle symbols. 

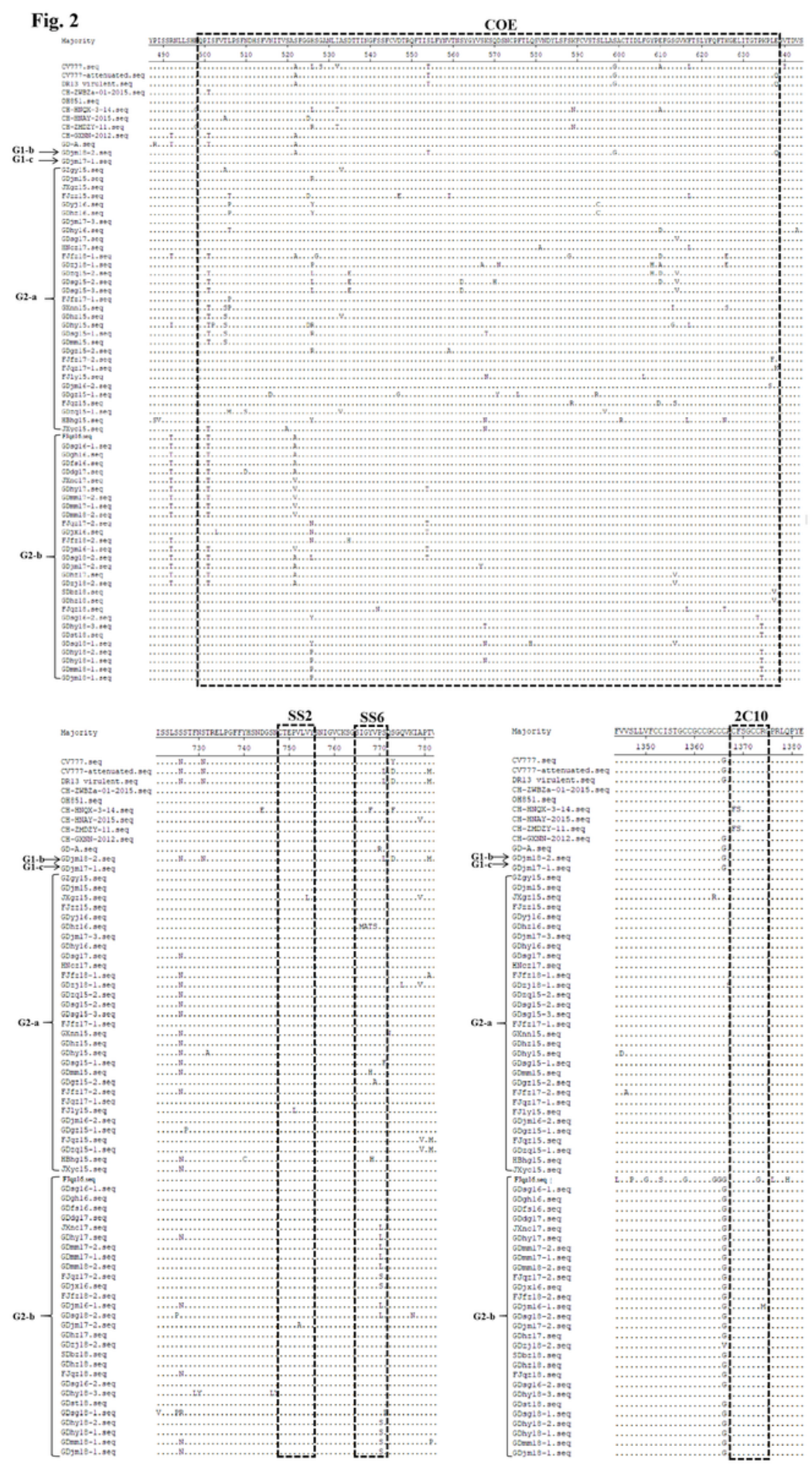

\section{Figure 2}

Amino acid sequence analysis of the neutralizing epitope in the $S$ protein The amino acid sequence alignment of S protein neutralizing epitopes of isolated strains and reference strains using the Clustal W method. 
Fig.3
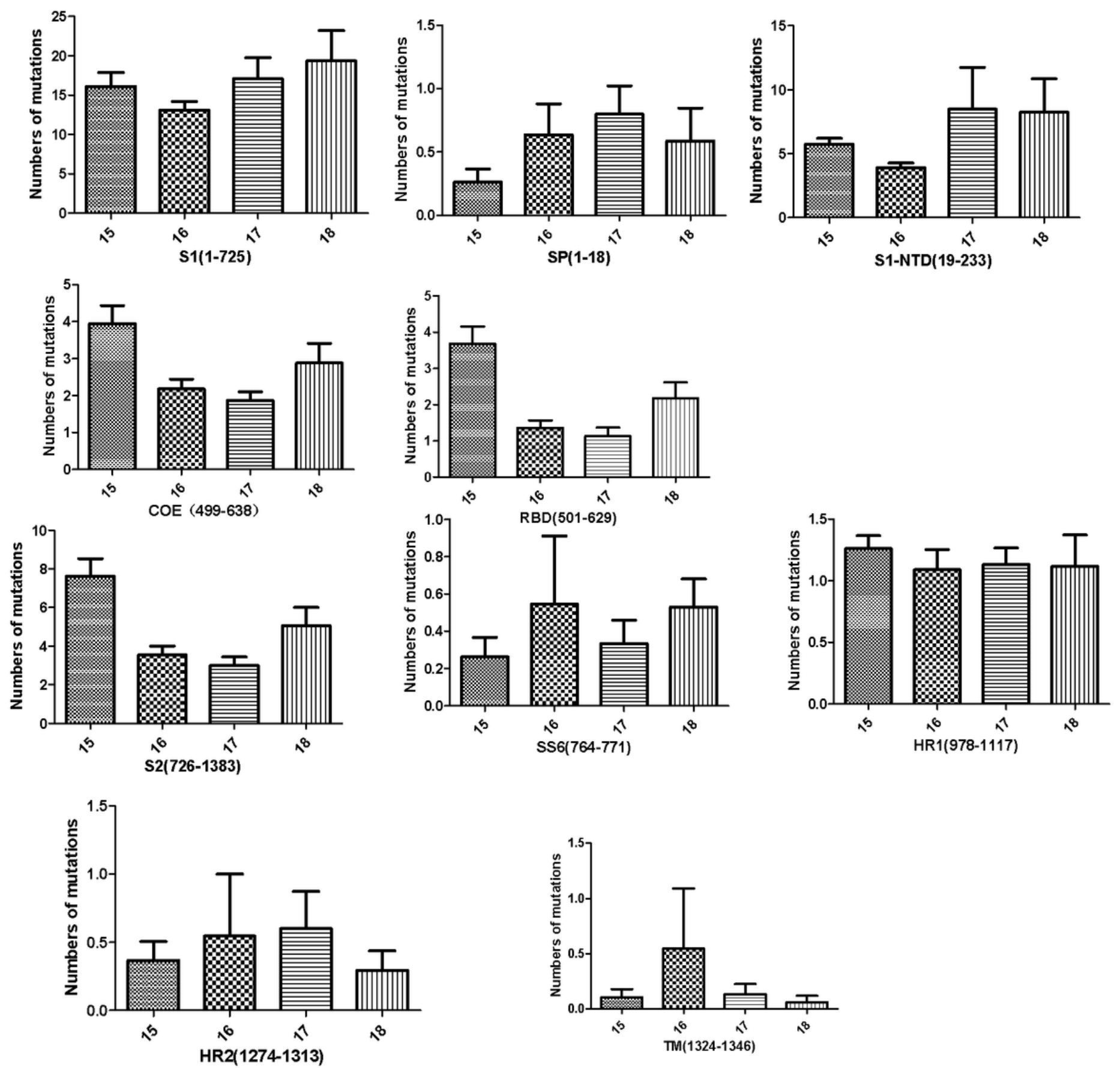

Figure 3

Number of amino acid mutations in different domains in the $\mathrm{S}$ protein The number of amino acid mutations in different domains in the S protein, including the $S 1$ subunit (residue 1-725), the $S 2$ subunit (residue 726-1383), the signal peptide (SP, residues 1-18), the N-terminal domain of S1 (S1-NTD, residue 19-233), neutralizing epitopes (COE, residues 499-638; SS2, residues 748-755; SS6, residues 764-771; 2C10, residues 1368-1374), two heptad repeat regions (HR1, residues 978-1117 and HR2, residues 1274-1313), and the transmembrane domain (TM, residues 1324-1346) 
Fig. 4

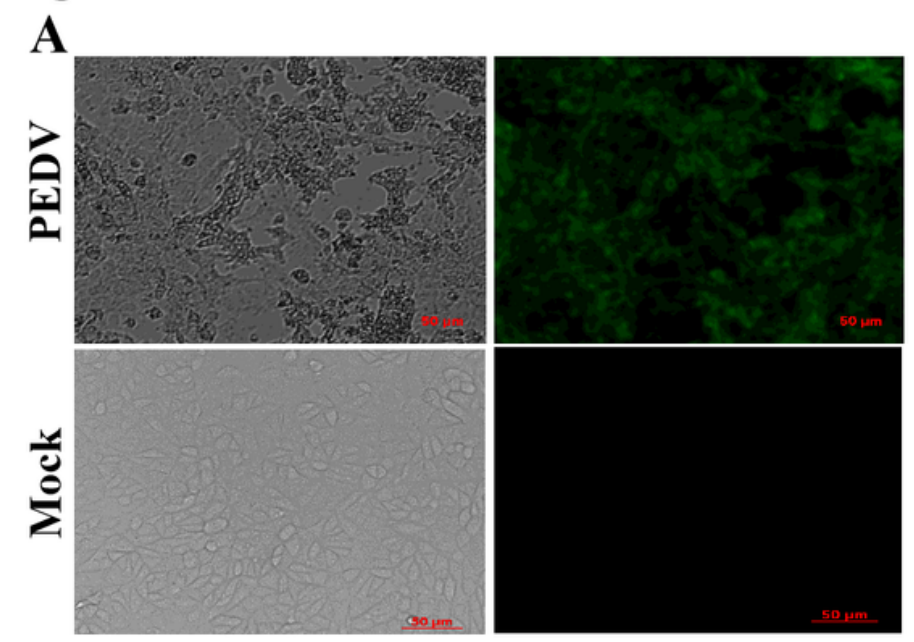

\section{B}

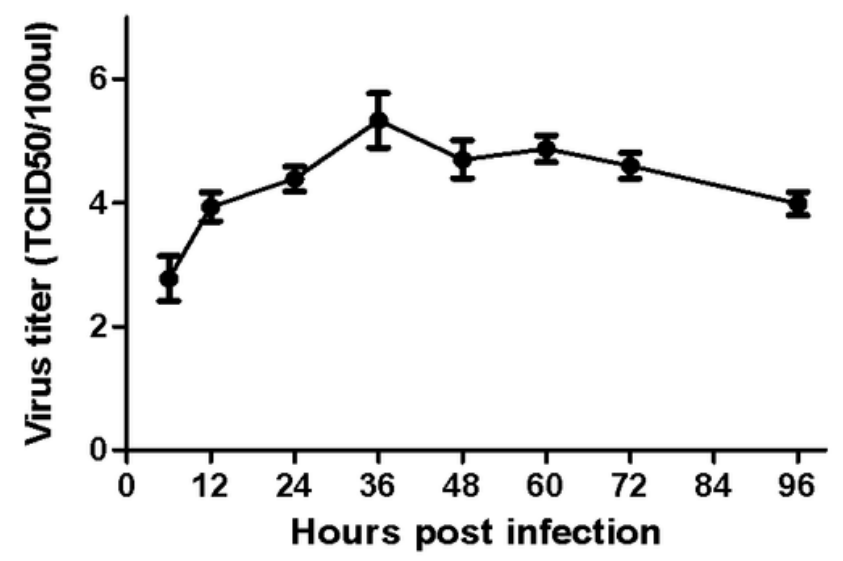

Figure 4

Detection and proliferation kinetic curve of PEDV strain GDgh16 (A) Identification of GDgh16 in Vero cells. The CPE of GDgh16 at 24 hpi was observed by white light and was tested by IFA using mAb against the PEDV N protein. (B) Proliferation kinetic curve of the PEDV strain GDgh16. Vero cells were infected with GDgh16 at MOI of 0.01 . The cells and culture solution were collected at 6 hpi, 12 hpi, 24 hpi, 36 hpi, 48 hpi, 60 hpi and 72 hpi, frozen, thawed and centrifuged. Then, the supernatant was collected, and the TCID50 was detected. 


\section{Fig. 5}
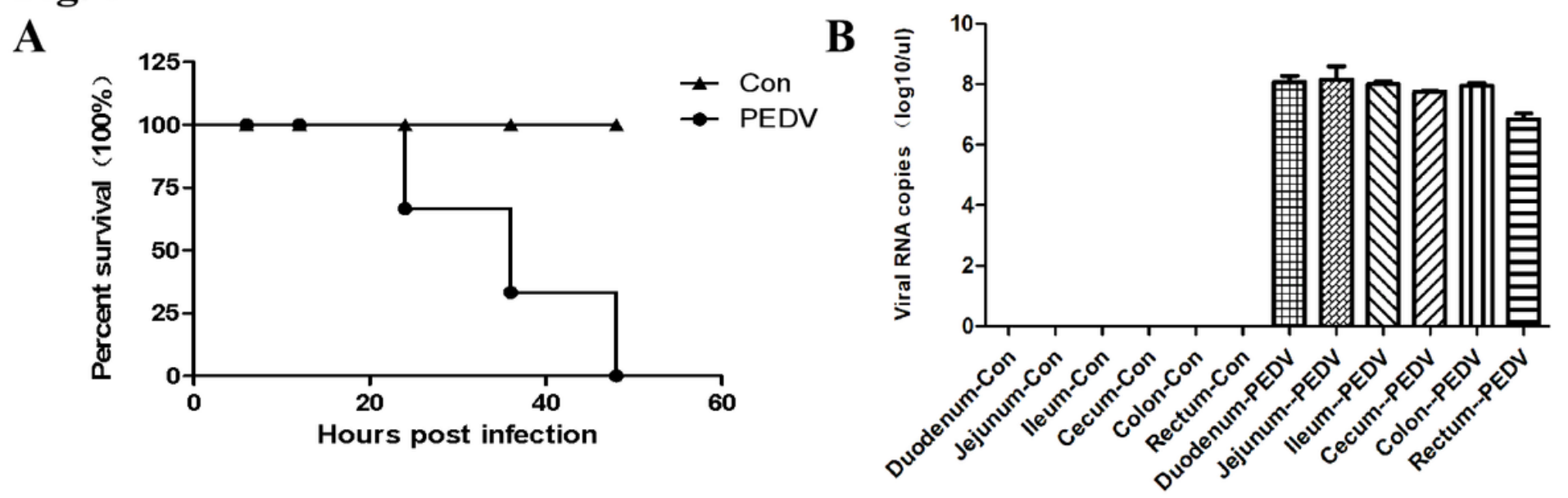

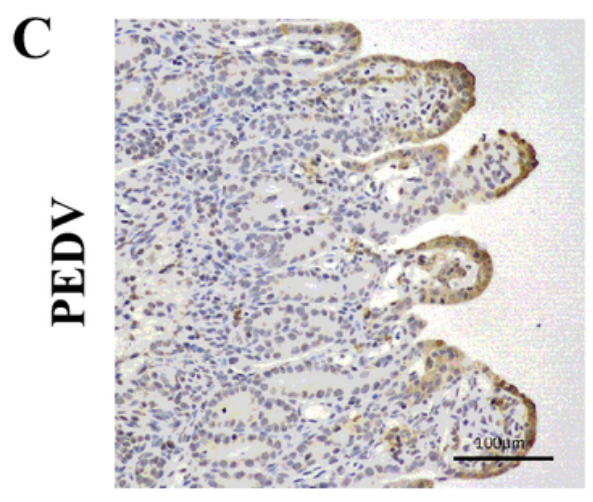

Duodenum

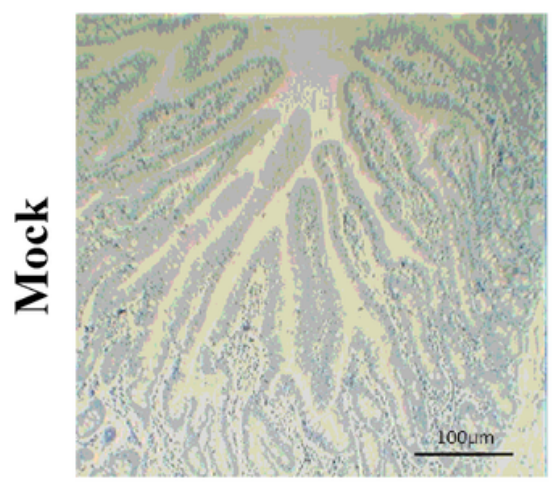

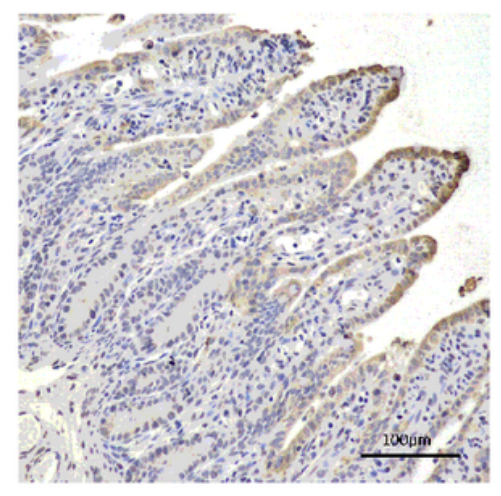

Jejunum

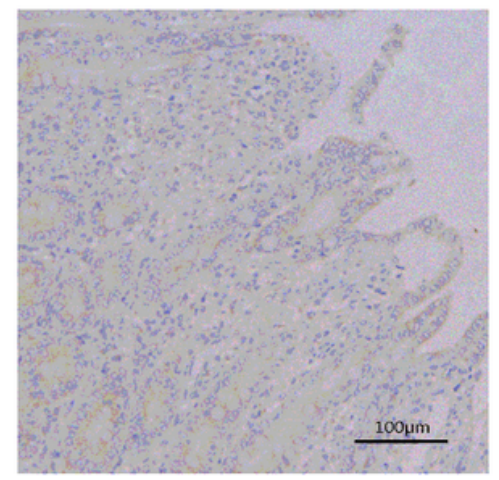

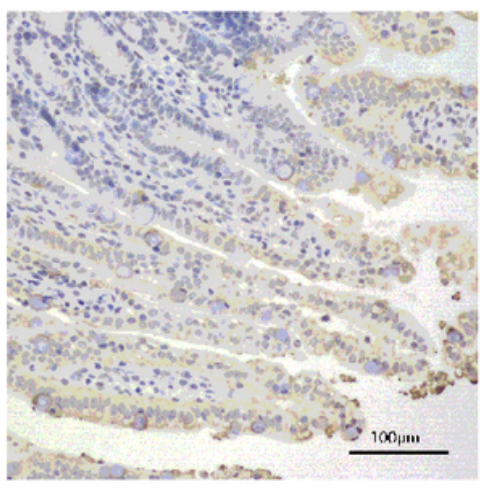

Ileum

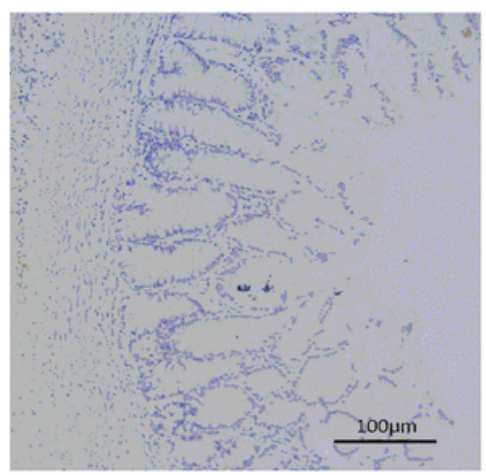

Figure 5

Pathogenicity analysis of GDgh16. (A) The survival rate of piglets in each group. (B) Quantification of the viral load in different parts of the intestine. The different parts of the intestine were collected, and the viral load was quantified by the TaqMan real-time RT-PCR targeting the PEDV N gene. (C) Immunohistochemical detection of intestines. The duodenum, jejunum and ileum of each group were stained with the PEDV monoclonal antibody against the $\mathrm{N}$ protein (1:1000 dilution). 